\title{
Mechanisms of cell death in canine parvovirus-infected cells provide intuitive insights to developing nanotools for medicine
}

This article was published in the following Dove Press journal:

International Journal of Nanomedicine

18 June 2010

Number of times this article has been viewed

\section{Jonna Nykky \\ Jenni E Tuusa \\ Sanna Kirjavainen \\ Matti Vuento \\ Leona Gilbert}

Nanoscience Center and Department of Biological and Environmental Science, University of Jyväskylä, Finland
Correspondence: Leona Gilbert

PO Box 35, Fl-400I 4 University

of Jyväskylä, Finland

Tel +358 I4 2604208

Fax +358 I4 260232 I

Email leona.k.gilbert@jyu.fi

\begin{abstract}
Viruses have great potential as nanotools in medicine for gene transfer, targeted gene delivery, and oncolytic cancer virotherapy. Here we have studied cell death mechanisms of canine parvovirus (CPV) to increase the knowledge on the CPV life cycle in order to facilitate the development of better parvovirus vectors. Morphological studies of CPV-infected Norden laboratory feline kidney (NLFK) cells and canine fibroma cells (A72) displayed characteristic apoptotic events. Apoptosis was further confirmed by activation of caspases and cellular DNA damage. However, results from annexin V-propidium iodide (PI) labeling and membrane polarization assays indicated disruption of the plasma membrane uncommon to apoptosis. These results provide evidence that secondary necrosis followed apoptosis. In addition, two human cancer cell lines were found to be infected by CPV. This necrotic event over apoptotic cell death and infection in human cells provide insightful information when developing CPV as a nanotool for cancer treatments.
\end{abstract}

Keywords: canine parvovirus, apoptosis, necrosis, nanoparticle, virotherapy

\section{Introduction}

Autonomous parvoviruses are small nonenveloped viruses that have oncolytic capabilities and have been exploited as a nanotool in medicine. Parvoviruses have been used as an antitumor agent, immune cell activator, and as a targeted gene vector. ${ }^{1-5}$ In addition, CPV virus-like particles have been employed in delivery of drugs. ${ }^{6} \mathrm{On}$ the other hand, parvovirus $\mathrm{H}-1$ has also been utilized in oncolytic virotherapy. ${ }^{7,8}$ Oncolytic virotherapy means the use of lytic viruses to kill tumor cells while normal cells are not infected by the virus. This kind of new cancer therapy is needed to treat cancers that are resistant to conventional cancer treatments. ${ }^{9}$ Lysis of cancer cells releases tumor-associated antigens that induce anticancer immunity and this type of treatment can also be seen as a cancer vaccine. Advantage of this effect is immune memory to prevent relapse and metastasis. ${ }^{10}$ In order to use virotherapy it is important to understand how these virus nanotools behave intracellularly.

There are three major morphologically and biochemically distinct types of cell death: apoptosis (type 1 cell death), autophagy (type 2 cell death), and necrosis (type 3 cell death). ${ }^{11}$ Apoptosis is characterized by nuclear and cytoplasmic condensation, maintenance of membrane integrity, and formation of apoptotic bodies; whereas, necrotic cells swell, lose plasma membrane integrity rapidly, and eventually lyse. Autophagic cell death is characterized by formation of vacuoles surrounded by a double membrane and by a lack of chromatin condensation. ${ }^{1-14}$ In vivo apoptotic bodies are rapidly phagocytized. However, when studied in vitro late apoptotic cells may lose 
membrane integrity and become necrotic. ${ }^{14}$ This terminal phase of in vitro cell death, called secondary necrosis, occurs in apoptotic cells in the absence of phagocytic cells. Because secondary necrosis is an end stage of apoptosis it can be discriminated from primary necrosis by occurrence of apoptotic and necrotic cell death parameters. ${ }^{15,16}$ Many viruses are known to cause these types of cell death, for example HIV (apoptosis), ${ }^{17}$ hepatitis $\mathrm{C}$ virus (autophagy), ${ }^{18}$ bovine parvovirus (necrosis), ${ }^{19}$ and porcine reproductive and respiratory syndrome virus (secondary necrosis). ${ }^{20}$

A parvovirus infection has multiple effects on host cells depending on the infecting virus and the type of cell used. Infection arrests cell cycle ${ }^{21-24}$ and induces cell death through different cell death mechanisms. Aleutian mink disease virus, ${ }^{25}$ feline panleukopenia virus (FPLV) ${ }^{26}$ human parvovirus $\mathrm{B} 19,{ }^{27-29}$ parvovirus $\mathrm{H}-1,{ }^{30}$ and rat parvovirus ${ }^{31}$ have been reported to induce apoptotic cell death while bovine parvovirus infected cells are necrotic. ${ }^{19}$ On the other hand apoptosis induced in $\mathrm{H}-1$ infection progresses to a necrotic cell death state in specific cell types. ${ }^{32}$ However, H-1 infected apoptosis-resistant glioma cells die by nonapoptotic mechanism by gathering of lysosomal cathepsins in cytoplasm. ${ }^{33}$ Also a minute virus of mice (MVM) infection induces cell death different from conventional apoptotic/necrotic cell death pathways by interfering with the cytoskeleton and changing the substrate specificity of casein kinase II. ${ }^{34}$ Due to the fact that CPV is being investigated as a novel nanomaterial for gene delivery and tumor targeting, it is of great interest to have a clearer understanding of how this virus causes cell death.

CPV and FPLV are classified as host range variants of feline parvovirus (FPV). ${ }^{35,36}$ The linear single-stranded DNA genome of CPV codes for two structural proteins, VP1 and VP2, and two nonstructural proteins NS1 and NS2. ${ }^{37} \mathrm{CPV}$ causes mostly enteritis and myocarditis in puppies, but also leukopenia may be observed in dogs with a CPV infection. ${ }^{38}$ $\mathrm{CPV}$ uses transferrin receptor ( $\mathrm{TfR}$ ) to enter canine or feline cells and has been shown to bind to human TfR, but there is no evidence of CPV infecting humans. ${ }^{39}$ Interestingly, apoptotic cells have been observed in studies concerning in vivo tissue samples from CPV- and FPLV-infected animals. ${ }^{40}$ In cultured canine and feline lymphocytes, a CPV or FPLV infection, respectively, displayed characteristics of cell death caused by apoptosis. ${ }^{26}$ Here we have examined the mechanism of cell death to assist the development of CPV vectors for use in virotherapy. Although CPV has a limited host range, it has previously been shown to be able to infect a human cancer cell line. ${ }^{39}$ This work was extended here.

\section{Material and methods \\ Cells and virus}

Two permissive cell lines widely used in CPV studies were used. NLFK cells and a canine fibroma cell line A72 (gifts from Colin Parrish, Cornell University, Ithaca, NY) were grown in Dulbecco's modified Eagle's medium. Human cell HepG2, a hepatocellular carcinoma cell line, was cultured in Hepatocyte Wash Media (Invitrogen, Carlsbad, CA) with 1\% L-glutamine (Invitrogen), and HeLa, a cervical adenocarcinoma cell line, was maintained in Eagle's minimum essential medium. All cell line media were supplemented with $10 \%$ fetal calf serum (PAA Laboratories, Pasching, Austria), 1\% PenStrep (Invitrogen), and incubated at $37^{\circ} \mathrm{C}$ in $5 \% \mathrm{CO}_{2}$. CPV type 2, derived from an infectious clone as previously described, ${ }^{41}$ was propagated in NLFK cells in $500 \mathrm{~cm}^{2}$ cell culture flasks (Nunc, Roskilde, Denmark) for seven days and then stored at $-20^{\circ} \mathrm{C}$. Cell debris was removed from $300 \mathrm{~mL}$ of virus culture medium by centrifugation and the supernatants were concentrated by ultrafiltration $(30 \mathrm{kDa}$ filter; Millipore Corporation, Bedford, MA). The virus was pelleted by ultracentrifugation at $173,000 \times \mathrm{g}$ for one hour and resuspended in $1 \mathrm{~mL}$ of phosphate-buffered saline (PBS) $\mathrm{pH}$ 7.4. The suspension was sonicated with low power and extracted with chloroform. The CPV-containing aqueous layer was used to infect permissive cells at multiplicity of infection (MOI) 50 and human cancer cell lines at MOI 0.1, determined by titration methods.

\section{Differential interference contrast microscopy}

To show morphological changes of cells in a CPV infection, differential interference contrast (DIC) microscopy was used. NLFK and A72 cells grown to $80 \%$ confluency on coverslips (diameter, $13 \mathrm{~mm}$ ) were inoculated with CPV for 15 minutes at $37^{\circ} \mathrm{C}$ and incubated for 12 to 72 hours. Unfixed slips were mounted and immediately examined with a laser scanning fluorescence microscope (LSM 510; Zeiss Axiovert 100 M; Carl Zeiss MicroImaging, Inc., New York, NY).

\section{Flow cytometry for DNA content}

To study cell cycle of CPV-infected cells flow cytometry was used. ${ }^{42}$ CPV- or mock-infected NLFK and A72 cells were harvested by trypsinization, washed with PBS, and fixed with ice cold $70 \%$ ethanol. Fixed cells were incubated with $0.15 \mathrm{mg} / \mathrm{mL}$ Ribonuclease A (Roche, Mannheim, Germany) for 30 minutes at $37^{\circ} \mathrm{C}$ and labeled with $50 \mu \mathrm{g} / \mathrm{mL}$ propidium iodide (Molecular Probes, Inc., Eugene, OR.) for 15 minutes. Samples were analyzed with FACSCalibur 
(Becton Dickinson, Franklin Lakes, NJ) with a $488 \mathrm{~nm}$ laser line and analyzed using Cell Quest (Becton Dickinson) and FlowJo (Tree Star, Inc., Ashland, OR) software. A total of $10^{4}$ cells were analyzed in each assay to create a cytogram. These experiments were repeated four times with similar observations and one experiment was utilized for representation.

\section{Flow cytometric analyses for differentiating the type of cell death}

The type of cell death was analyzed with annexin V and PI double staining. ${ }^{43}$ NLFK and A72 cells grown in $8.8 \mathrm{~cm}^{2}$ dishes (Nunc) were CPV- or mock-infected and incubated for the indicated time points of 12 to 72 hours. To doublelabel the cells, $10^{5}$ trypsinized cells were washed with annexin $\mathrm{V}$ binding buffer (10 mM 4-(2-hydroxyethyl)-1piperazineethanesulfonic acid (HEPES), $140 \mathrm{mM} \mathrm{NaCl}$ and $2.5 \mathrm{mM} \mathrm{CaCl}_{2}, \mathrm{pH} 7.4$ ). Resuspended cells in $100 \mu \mathrm{L}$ of binding buffer were stained by adding $5 \mu \mathrm{L}$ of annexin $\mathrm{V}$ Alexa Fluor 488 (Molecular Probes, Inc.) and with $3 \mu \mathrm{M}$ PI. As a positive control, cells were treated with $0.5 \mu \mathrm{M}$ staurosporine (STS; Sigma, St. Louis, MO) for 16 hours to induce apoptosis. After 15 minutes incubation at room temperature, fluoresence was measured by flow cytometry using a FACSCalibur with a $488 \mathrm{~nm}$ laser line and Cell Quest software (Becton Dickinson). A total of $10^{4}$ cells were analyzed in each assay to create a cytogram. Results were analyzed with FlowJo software (Tree Star). Experiments were repeated five times with similar observations, and results of one experiment are shown.

\section{Caspase assays}

In order to indicate the mechanism of apoptosis occuring in CPV-infected cells caspase activation was assayed. Caspase-Glo 8, 9, and 3/7 assay systems (Promega, Madison, WI) were used according to manufacturer's instructions. Cells were grown and infected at MOI 50 on 96-well plate (Greiner Bio-One, Maybachstrasse, Germany). At the indicated time points (6 to 72 hours post-infection), caspase reagent was added to wells and incubated at room temperature for one hour in the dark. Luminescence was measured with Wallac Victor ${ }^{2} 1420$ Multilabel counter (PerkinElmer, Waltham, MA). STS- ( $1 \mu \mathrm{M}, 12$ hours; sigma) treated cells were used as a positive control and caspase inhibitors were used to inhibit caspase activation. Caspase inhibitor Z-VADFMK (Promega) was used to inhibit caspase 3/7. Inhibitors for caspase 8 (Z-IETD-FMK) and 9 (Z-LEHD-FMK) were from Caspase-family inhibitor set IV (BioVision, Inc,) Mountain View, CA. Experiments were repeated three times.
Statistical analysis was performed with Kruskall-Wallis analysis (KaleidaGraph software, Synergy Software, Reading, PA). Significance level was set to 0.05 .

\section{Immunofluorescence microscopy}

To study molecular and biochemical changes in infected cells, NS1 and H2A.X proteins were observed by immunofluorescence microscopy. CPV- and mock-infected NLFK cells grown on coverslips were fixed with ice cold methanol and double-labeled with biotinylated monoclonal mouse anti-phospho-histone H2A.X antibody (clone JBW301, Upstate Biotechnology, Inc., Lake Placid, NY) and with a monoclonal mouse antibody to the nonstructural protein 1 (NS1) of CPV (gift from Colin Parrish). Biotinylated H2A.X antibody was detected with a streptavidin Alexa Fluor 488 conjugate (Molecular Probes, Inc.) while the NS1 antibody was conjugated to Cy5 (Molecular Probes, Inc.) according to manufacturer's instructions. The samples were examined with a laser scanning fluorescence microscope (LSM 510; Zeiss Axiovert 100 M, Carl Zeiss, Inc.) by using the excitation and emission settings appropriate for the dye used. Infectivity was determined by calculating the ratio of cells with fluorescent nuclei to the total number of cells $(\mathrm{n}=1,000)$. KaleidaGraph software (Synergy Software) was used to calculate results and draw graphs.

\section{Electron microscopy}

Nuclear fragmentation was assessed using electron microscopy. NLFK cells grown on $8.8 \mathrm{~cm}^{2}$ dishes (Nunc) were inoculated with $\mathrm{CPV}$ for 15 minutes at $37^{\circ} \mathrm{C}$ and incubated for 24 to 72 hours. After appropriate times per infection, cells were rinsed three times with $0.1 \mathrm{M} \mathrm{PBS} \mathrm{pH}$ 7.4 and fixed with $2.5 \%$ glutaraldehyde in $0.1 \mathrm{M}$ PBS for one hour. Cells were washed with $0.1 \mathrm{M}$ PBS pH 7.4 and postfixed in $1 \%$ osmium tetroxide in $0.1 \mathrm{M}$ PBS pH 7.4 for one hour at $4^{\circ} \mathrm{C}$. Samples were dehydrated in ethanol, stained with uranyl acetate, and embedded in Epon LX-112 (Ladd Research Industries, Williston, VT). Thin sections were cut and samples were viewed at $60 \mathrm{kV}$ with a JEOL JEM-1200EX transmission EM (Jeol Ltd., Tokyo, Japan).

\section{DNA fragmentation}

DNA fragmentation was assessed as previously described. ${ }^{44}$ Floating and adherent cells were collected and embedded in $1.5 \%$ low melting point agar (Boehringer Mannheim, Mannheim, Germany) and treated with lysis buffer (50 mM NaCl, 20 mM Tris-HCl, pH 8.0, 20 mM EDTA, $0.5 \%$ sodium sarcosyl, $50 \mu \mathrm{g} / \mathrm{mL}$ Ribonuclease A (Roche), 
$100 \mu \mathrm{g} / \mathrm{mL}$ proteinase $\mathrm{K}$ [Roche] for one hour at $37^{\circ} \mathrm{C}$. Cells were washed with buffer tris/borate/ethylenediaminetetraacetic acid (EDTA) (TBE) buffer and resolved in 1\% agarose gel.

\section{Flow cytometric analyses of membrane integrity}

To analyze if a CPV infection has an effect on plasma and mitochondria membrane potentials, 3,3'-dihexyloxacarbocyanine iodide ( DiOC $_{6}(3)$; Molecular Probes, Inc.) and DePsipher (R\&D Systems, Inc., Minneapolis, MN) were used. ${ }^{45}$ NLFK cells grown in $8.8 \mathrm{~cm}^{2}$ dishes (Nunc) were CPV- or mockinfected, and incubated for 12 to 24 hours. $\operatorname{DiOC}_{6}(3)$ was added to trypsinized cells at a final concentration of $20 \mathrm{nM}$ and incubated for 15 minutes at $37^{\circ} \mathrm{C}$. As a positive control for each sample, cells were also labeled in the presence of $100 \mu \mathrm{M}$ protonophore carbonyl cyanide $m$-chlorophenylhydrazone (CCCP; Sigma). For analysis of mitochondria membrane integrity, DePsipher was added to trypsinized cells at a final concentration of $10 \mu \mathrm{g} / \mathrm{mL}$ and incubated for 30 minutes at $37^{\circ} \mathrm{C}$. As a positive control, cells were also labeled in the presence of $100 \mathrm{nM} \mathrm{K}^{+}$-selective ionophore valinomycin (Sigma). Stained cells were analyzed with flow cytometry using a FACSCalibur with a $488 \mathrm{~nm}$ laser line and Cell Quest software (Becton Dickinson). A total of $10^{4}$ cells were analyzed in each assay to create the cytograms. Results were analyzed with FlowJo software (Tree Star). These experiments were repeated four times with similar observations, and one experiment was utilized for representation.

\section{Flow cytometry studies for expression of NSI protein in human cells}

HepG2 and HeLa cells were collected by trypsinization with $0.5 \%$ Trypsin/EDTA (Invitrogen) in PBS (Invitrogen) at 24 hours post-infection, washed once with fresh media $(500 \mu \mathrm{L})$ and then washed again with PBS. For NS1 expression analysis, $5 \times 10^{5}$ of CPV- or mock-infected cells at MOI 0.1 were resuspended in $500 \mu \mathrm{L}$ of ice-cold PBS and fixed with ice-cold methanol. Immunolabelling proceeded with a monoclonal mouse antibody to the nonstructural protein 1 (NS1) of CPV (gift from Colin Parrish) and detected with a goat anti-mouse Alexa Fluor 488 conjugate (Molecular Probes, Inc.). All samples were analyzed on the FACSCalibur flow cytometer (Becton Dickinson), data collected using Cell-Quest software (Becton Dickinson), and statistical analysis completed by FlowJo software (Tree Star).

\section{Results}

\section{General course of oncolytic behavior}

Both cell lines, NLFK and A72, have been used in several studies concerning canine parvovirus infection. ${ }^{46-50}$ DIC microscopy of these cell lines revealed that CPV infection induced cytopathic effects faster in NLFK cells than in A72 cells (Figure 1). Only a minority of the CPV-infected NLFK cells were rounded at 24 hours post infection, but at 48 hours post infection most of the cells had morphological changes, cell shrinkage, condensed cytoplasm, and immense cell detachment occurring (Figure 1a). In A72-infected cells, roundness as well as detachment was observed at 48 hours post infection and the cell changes were more evident at 72 hours post infection (Figure 1b). Immunofluorescence studies showed that CPV antigens (NS1 protein) were found in the nucleus in $30 \%$ of NLFK cells at 12 hours post-infection, and at 24 hours post-infection almost all the cells were infected (Figure 5a). In A72 cells only a minority of the cells were infected at 24 hours post-infection, but at 48 hours post-infection 58\% stained positive for NS1 (data not shown). Since time points of 12 to 24 hours post-infection in NLFK-infected cells indicated severe

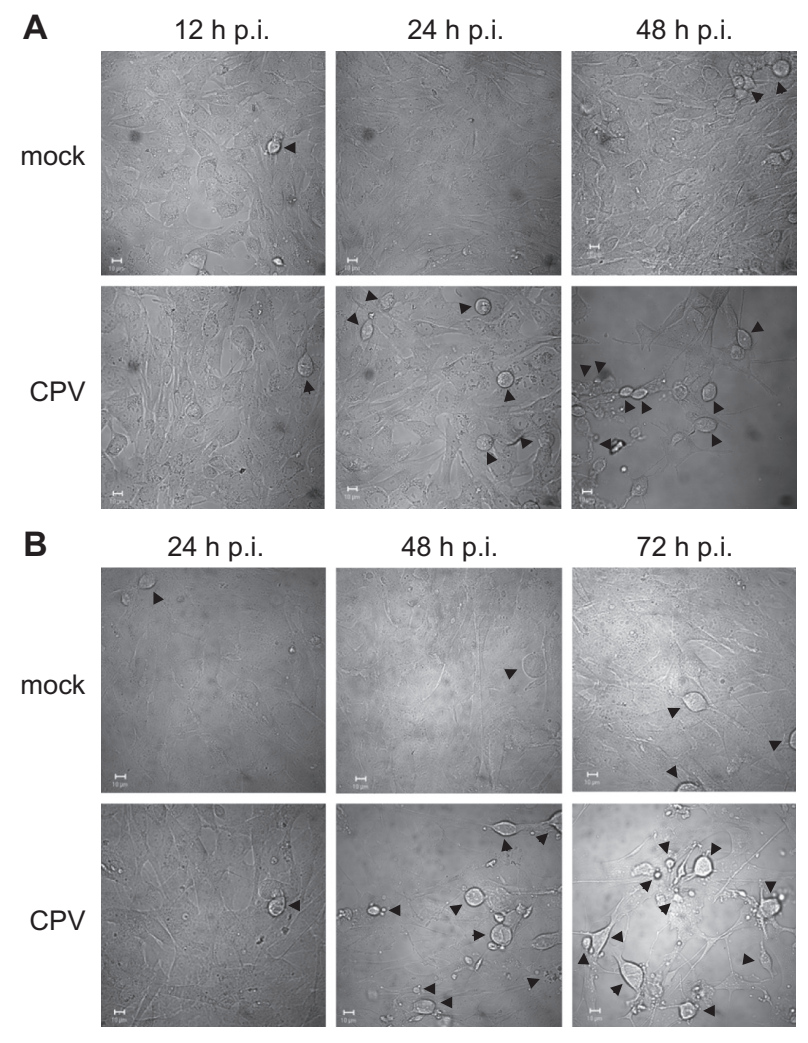

Figure I Morphological changes of CPV-infected cells. Differential interference contrast microscopy pictures of mock- and CPV-infected cells. (a) NLFK cells at 12 hours, 24 hours, and 48 hours post infection. (b) A72 cells at 24 hours, 48 hours, and 72 hours post infection. Arrowheads point to rounded cells. Bars $10 \mu \mathrm{m}$. 
morphological changes and time points of 24 to 72 hours post-infection in A72-infected cells showed similar changes, these time points were used respectively for experiments to study cell death mechanisms.

\section{CPV induces cell cycle arrest}

Analysis of the DNA content of CPV-infected NLFK and A72 cells showed that cells accumulated progressively at the $\mathrm{S}$ phase (Figure 2). This $\mathrm{S}$ arrest was found to be time dependent for both cell lines. The mock-infected NLFK cells showed $19.3 \%$ of the cells in S phase whereas CPVinfected cells showed $30.4 \%$ after 12 hours, which further increased to $50.2 \%$ after 24 hours. The mock-infected A72 cells showed $6.4 \%$ of the cells in S phase, whereas CPVinfected cells showed $10.3 \%$ after 24 hours which further increased to $16.7 \%$ after 72 hours. The mock-infected NLFK cells showed $64.2 \%$ of the cells in $\mathrm{G}_{0} / \mathrm{G}_{1}$ phase whereas CPVinfected cells showed $55.9 \%$ after 12 hours, which further decreased to $18.5 \%$ after 24 hours. The mock-infected A72 cells showed $72.9 \%$ of the cells in $\mathrm{G}_{0} / \mathrm{G}_{1}$ phase, whereas CPV-infected cells showed $62.6 \%$ after 24 hours which further decreased to $25.6 \%$ after 72 hours, probably due to delayed effects of viral infection in this cell line. These results indicated that CPV infection arrests cell cycle at the $\mathrm{S}$ phase and CPV-infected cells accumulated unusually high amounts of DNA.

\section{Differentiating the type of cell death in CPV infected cells}

Annexin $\mathrm{V}$ is often used to study the translocation of phosphatidylserine from the inner leaflet of the plasma membrane to the outer leaflet in apoptotic cells. ${ }^{51}$ Thus double-labeling with annexin V with PI could be used to differentiate between different types of cell death. The cytogram of cells undergoing apoptosis (Figure 3, STS) as compared to mock-infected cells (Figure 3a, mock) in this double-labeling experiment should show early apoptotic cells in the lower right quadrant staining positive for annexin V and PI negative. Late apoptotic or necrotic cells are in the upper right quadrant positive for both PI and annexin $\mathrm{V}$ staining. Living cells in the lower left quadrant are negative for both fluorescent probes. Figure 3 a shows the results from such a double-labeling experiment with CPV-infected NLFK cells. A small increase of $8 \%$ in the proportion of double positive cells (late apoptotic/necrotic cells) could be seen already from 12 to 17 hours post infection. At 23 hours post infection, 50.6\% of the cells were late apoptotic or necrotic. When viewing the early apoptotic cells (lower right quadrant/annexin $\mathrm{V}$ positive) (Figure 3a), an increase from $2.43 \%$ to $22.9 \%$ for time points of 12 to 23 hours post infection was observed. As the course of infection progresses, an increase in early apoptotic cells accompanied by an increase of late apoptotic/necrotic cells

A

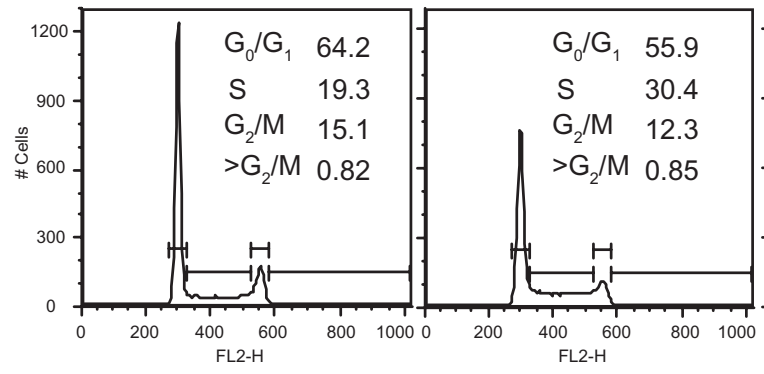

mock

$12 \mathrm{~h} \mathrm{p.i.}$

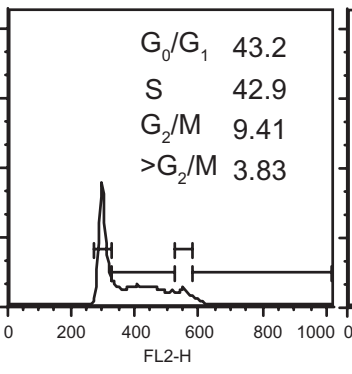

16 h p.i.

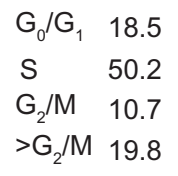

$\mathrm{G}_{0} / \mathrm{G}_{1} \quad 18.5$

S $\quad 50.2$

$\mathrm{G}_{2} / \mathrm{M} \quad 10.7$

$>\mathrm{G}_{2} / \mathrm{M} 19.8$

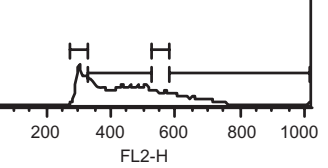

24 h p.i.

B
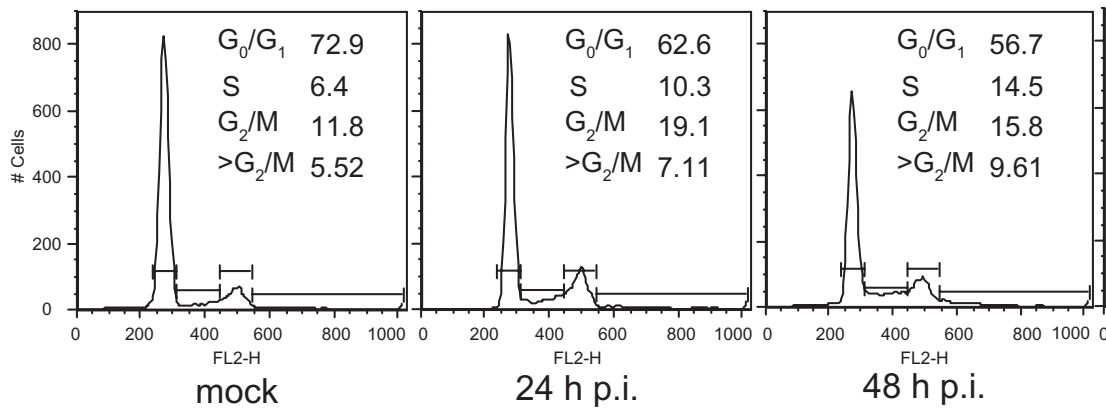

$\mathrm{G}_{0} / \mathrm{G}_{1} 25.6$

S $\quad 16.7$

$\mathrm{G}_{2} / \mathrm{M} \quad 13.5$

$>\mathrm{G}_{2} / \mathrm{M} 36.0$

Figure 2 Induction of cell cycle arrest. Flow cytometric analysis showing the DNA histograms of Pl-stained mock- and CPV-infected NLFK and A72 cells at indicated time points post infection. Percentage of cell population in each cell cycle phase is given. (a) Mock- (24 hours post infection) and CPV-infected (I2 hours, 16 hours, and 24 hours post infection) NLFK cells. (b) Mock- (72 hours post infection) and CPV-infected (24 hours, 48 hours, and 72 hours post infection) A72 cells. 

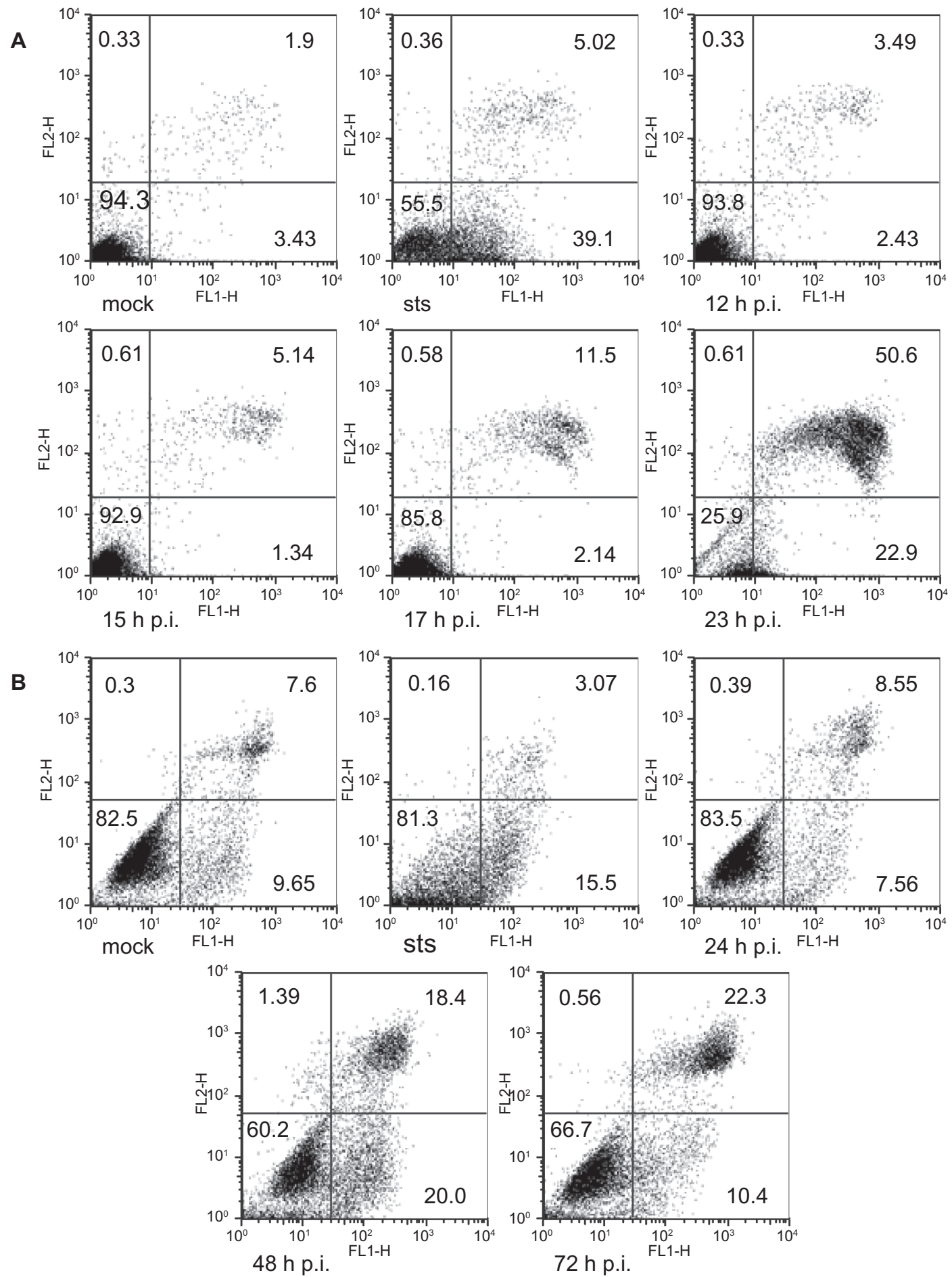

Figure 3 Flow cytometry analysis of annexin V- (FLI-H) and PI- (FL2-H) labeled cells. STS (0.5 $\mu$ M I 6 hours) was used as a positive control to induce apoptosis. Percentage of cells within each quadrant are indicated. (a) Cytograms of mock- ( 23 hours post-infection) and CPV-infected (I2 hours, I5 hours, I7 hours, and 23 hours post-infection) NLFK cells. (b) Cytograms of mock- (72 hours post-infection) and CPV-infected ( 24 hours, 48 hours, and 72 hours post-infection) A72 cells.

were similar to the findings seen in A72-infected cells (Figure 3b). From 24 to 48 hours post-infection, and then to 72 hours post-infection, there was a consistent increase from $8.55 \%$, to $18.4 \%$, and to $22.3 \%$, respectively, in the accumulation of late apoptotic or necrotic A72 cells. Early apoptotic cells did increase from $7.56 \%$ to $20 \%$ at 24 to 48 hours post-infection, but declined to $10.4 \%$ at 72 hours post infection. In both NLFK (data not shown) and A72 (Figure $3 \mathrm{~b}$ ) cell types, when the progress of the infection is pushed to later time points as in 72 hours post-infection, 
more cells were seen as late apoptotic or necrotic cells with a decrease in early apoptotic cells. These results indicated that apoptosis is initiated in CPV-infected cells, but later during the infection, the plasma membrane is damaged while the cells become necrotic.

\section{Caspase activation in CPV infected cells}

To investigate the apoptotic mechanism in CPV-infected cells, caspase activity assays were utilized. In CPV-infected NLFK cells caspase 9 was activated at 6 through 48 hours post infection and caspases 8 and 3/7 were activated at 12 through 48 hours post infection (Figure 4a). In CPV-infected A72 cells, caspases 9 and 3/7 were activated at 12 through 72 hours post infection, while caspase 8 activation was detected at 24 hours post infection (Figure 4b). In STS-treated NLFK and A72 cells, all these caspases were activated. When inhibitors were used the activation of caspases was lower (data not shown). Activation of caspases indicates apoptotic cell death.

\section{DNA damage in CPV-infected NLFK cells}

The accumulation of high levels of H2A.X phosphorylation coincide with severe DNA damage and is a very early and accurate indicator of apoptosis. ${ }^{52,53}$ Thus H2A.X immunolabelings were made to further study the apoptotic mechanism in NLFK cells. The percentage of phospho-H2A.X and NS1 positive cells were calculated (Figure 5a). Results showed that phosphorylation of histone increased with NS1 positive cells. At 24 hours post infection $76 \%$ of the cells had phosphorylated H2A.X, indicating induction of apoptosis in CPV-infected cells. Condensation of the nucleus and DNA were also detected with electron microscopy (Figure 5b). Condensed cytosol, nuclear envelope changes, fragmented nuclear components, as well as fragmented DNA could be detected at 24 hours post infection and at 48 hours post infection (Figure 5b). DNA was also fragmented as shown from electrophoresis of total cellular DNA after 24 hours post infection (Figure $5 \mathrm{c}$ lane 2). At 48 hours post infection the fragmentation of DNA was more severe (Figure 5c lane 3).

A
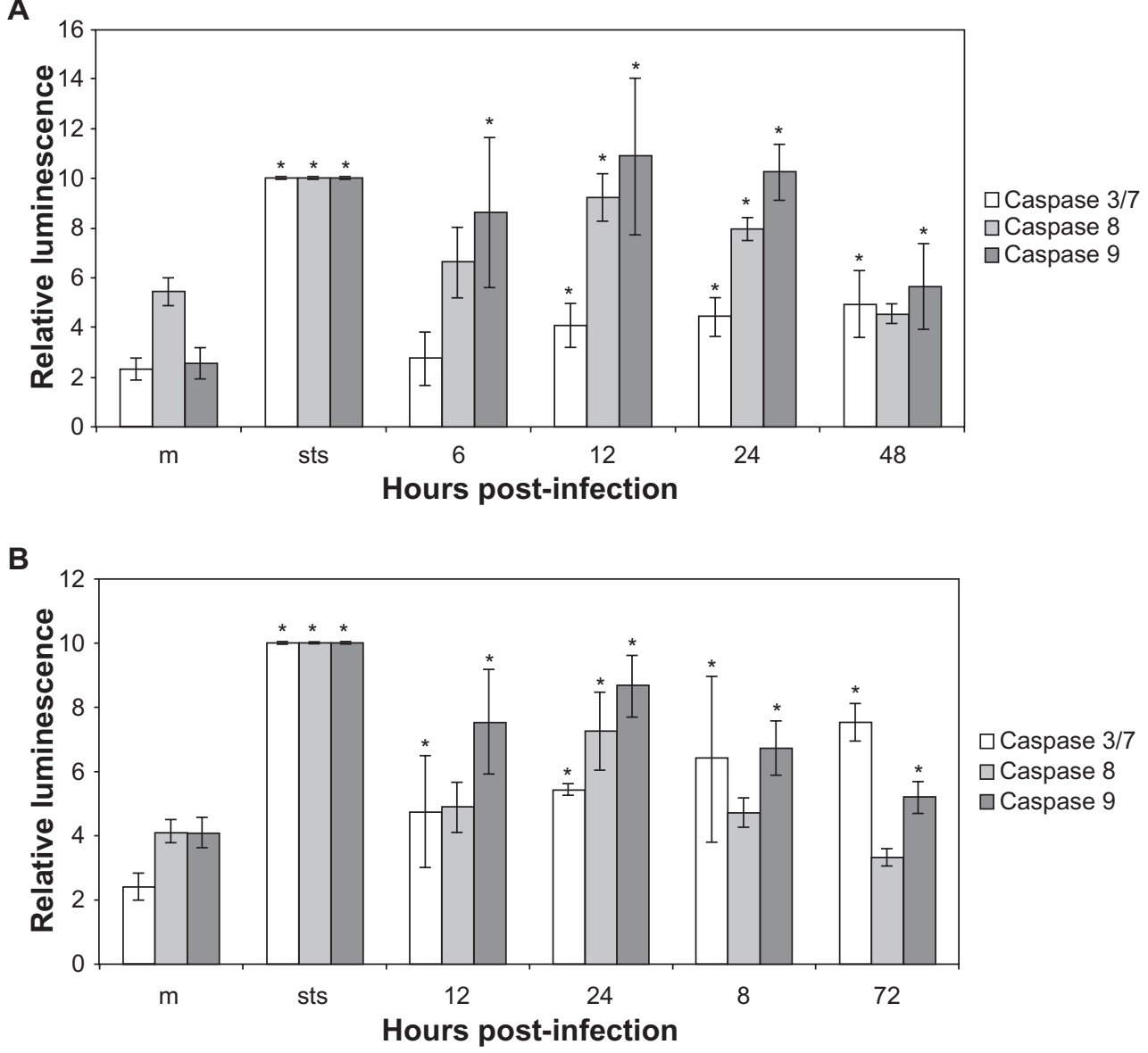

Figure 4 Caspase 3/7, caspase 8 , and caspase 9 activation in CPV-infected cells. (a) Mock- (24 hours post-infection) and CPV- (6 hours, 12 hours, 18 hours, 24 hours, and 48 hours post-infection) infected NLFK cells. (b) Mock- ( 24 hours post-infection) and CPV- (12 hours, 24 hours, 48 hours, and 72 hours post-infection) infected A72 cells.

Notes: STS (I.0 $\mu$ M 12 hours) was used as a positive control to induce apoptosis. Results from individual tests were normalized and averages were counted from triplicate results. Statistical significance is marked with $*(P<0.05)$. 
A

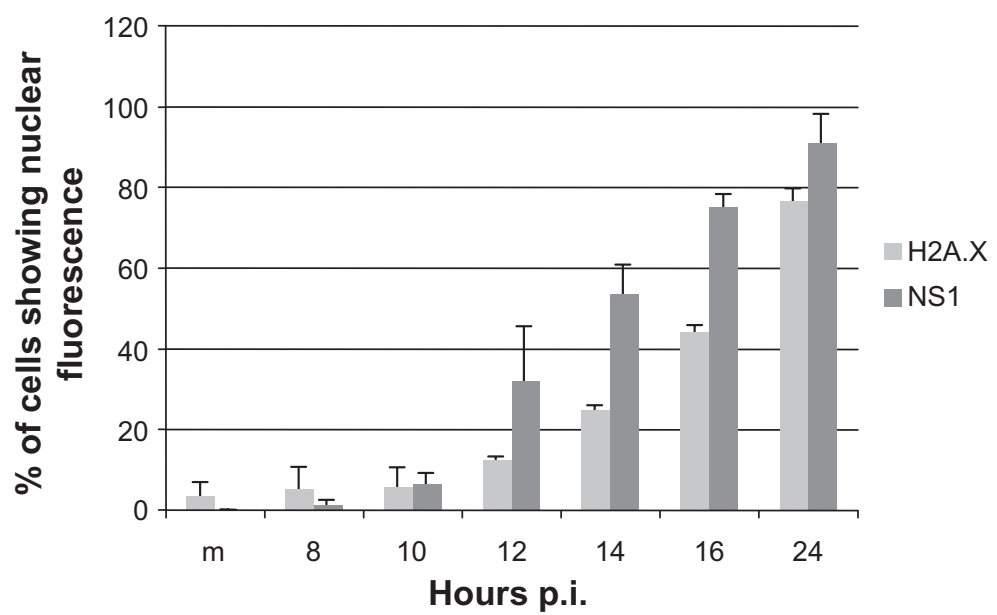

B

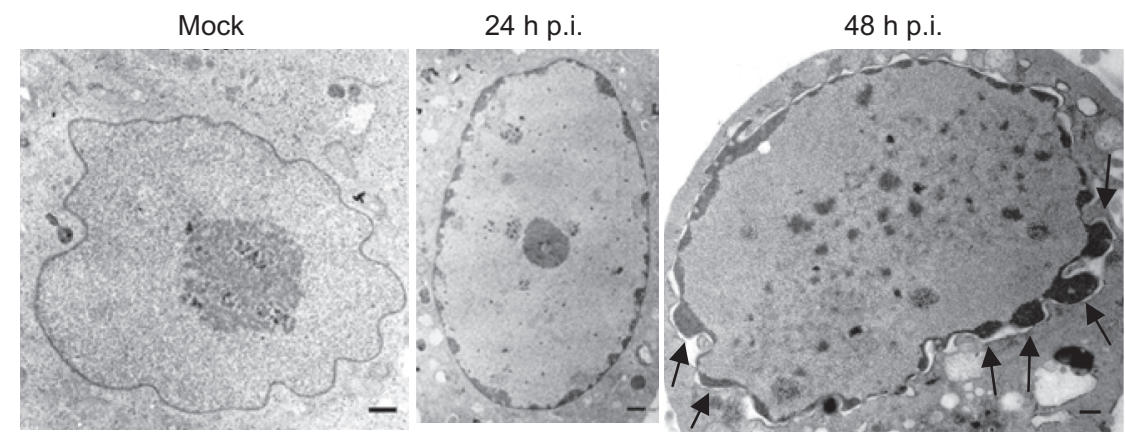

C

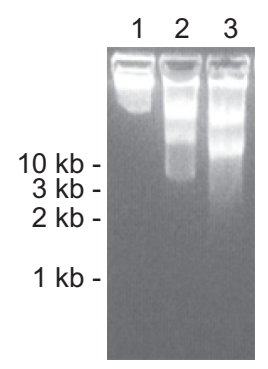

Figure 5 Biochemical and molecular changes in CPV-infected NLFK cells. (a) Phosphorylation of histone H2A.X. CPV-infected cells were fixed at different time points post infection and labeled with anti-phospho-histone H2A.X and anti-NSI antibodies (a marker of virus protein expression). Percentage of $\mathrm{H} 2 \mathrm{~A}$.X and NSI positive cells were calculated $(\mathrm{n}=1,000)$. $\mathrm{m}=$ mock-infected cells 24 hours post infection. Error bars indicate standard deviations. (b) and (c) Condensation and fragmentation of the nucleus and DNA during infection. (b) Transmission electron microscopy pictures of mock-infected (48 hours post-infection) and CPV-infected nucleus at 24 hours postinfection and 48 hours post-infection. Bars I $\mu \mathrm{m}$. Arrows show nuclear membrane blebbing. (c) Agarose gel electrophoresis showing fragmentation of DNA in infected cells. Lane I: mock-infected cells 48 hours post-infection, Lane 2: 24 hours post-infection, Lane 3: 48 hours post-infection.

\section{Mitochondria are involved in CPV-induced cell death}

Flow cytometric experiments that tested for the loss of mitochondrial membrane potential were completed to study the consequence of apoptosis in CPV-infected cells. $\operatorname{DiOC}_{6}(3)$ is known to respond to changes in both the mitochondrial and plasma membrane potential, but DePsipher measures only changes in the mitochondrial membrane potential. ${ }^{45}$ As shown in Figure 6a for NLFK-infected cells, membrane depolarization was detected at 17 hours post infection with a decrease in $\mathrm{DiOC}_{6}(3)$ fluorescence and depolarization had increased at
23 hours post-infection. DePsipher on the other hand aggregates upon mitochondrial membrane polarization forming a red fluorescent compound. When the mitochondrial membrane potential is disturbed, the dye reverts to its green monomeric form. A decrease of $65 \%$ to $14 \%$ in red fluorescence (FL2-H, upper left quadrant) was detected from 18 to 24 hours post infection, respectively. Green fluorescence (FL1-H, upper right quadrant) had increased from $28.3 \%$ to $73.8 \%$ from 18 to 24 hours post infection, respectively (Figure 6b), indicating that mitochondrial depolarization had occurred. Some red fluorescence was also seen in depolarized cells indicating polarized 
A
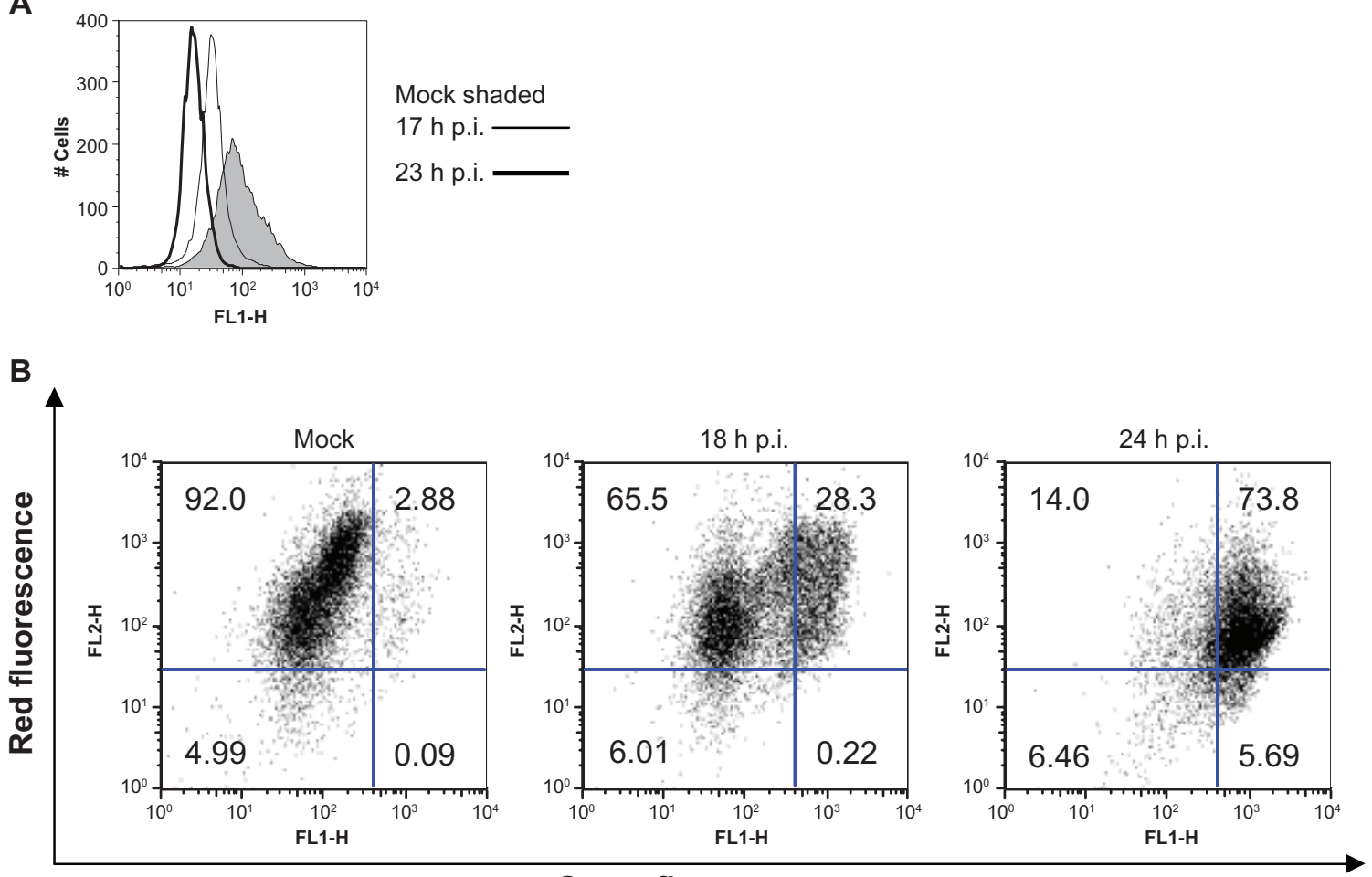

Green fluorescence

Figure 6 Depolarization of plasma membrane and mitochondrial membrane potential during CPV infection. (a) Mock- (23 hours post infection) and CPV-infected (I7 hours and 23 hours post infection) cells were labeled with DiOC6(3) and analyzed with flow cytometer. (b) Flow cytometry scatter diagrams of mock- (24 hours post infection) and CPV-infected ( 18 hours and 24 hours post infection) cells labeled with DePsipher. Percentage of cells within in each quadrant are indicated.

mitochondria (Figure 6b 18 hours and 24 hours). Depolarization of mitochondria indicates involvement of mitochondria in cell death pathway that can be either apoptotic or necrotic. ${ }^{11}$

\section{CPV infection of human tumor cell lines}

To confirm the relevance of CPV in human systems, a hepatocyte and cervical tumor cell lines were infected with CPV (Table 1). Since the expression of NS1 protein is an indicator of the synthesis and amplification of viral DNA replicative forms, monitoring of NS1 immunolabelled infected cells by flow cytometry was conducted. The NS1 expression analyzed by flow cytometry indicated that there is indeed infection of both cell lines, but at a much smaller amount compared to NLFK and A72 cells.

Table I CPV infection of human tumor cell lines

\begin{tabular}{lllll}
\hline & Mock I & Mock 2 & wt CPV I & wt CPV 2 \\
\hline HepG2 & 0.17 & 0.41 & 4.89 & 5.06 \\
HeLa & 0.54 & 0.39 & 9.92 & 11.4
\end{tabular}

Notes: Mock- (24 hours post-infection) and CPV-infected (24 hours post-infection) cells were immunolabeled with monoclonal anti-NSI, detected by anti-mouse Alexa 488 antibodies and analyzed with flow cytometer. Flow cytometry scatter diagrams of HepG2 and HeLa cells were used to gate 10,000 cells and the FLI channel used to obtain the level of NSI expression. Numbers represent percentage of cells displaying NSI expression.

\section{Discussion}

As a first step towards the use of CPV in virotherapy, its pathogenetic mechanisms of cell death was investigated. The observed morphological changes and immense cell detachment (Figure 1) provided initial evidence that cell death has occurred through apoptosis. ${ }^{11}$ When flow cytometry was used with annexin V and PI staining (Figure 3), characteristic early apoptotic and late apoptotic/necrotic cells were similar to those described for differentiating between the types of cell death. ${ }^{54}$ These findings indicated that the longer the infection occurs, more of the cells accumulated in the early apoptosis stage become late apoptotic or necrotic cells. This suggests that in a CPV infection, cells undergo early apoptosis and eventually accumulate as secondary necrotic cells.

In support of the view that apoptotic cell death was occurring, caspase 8, 9, and 3/7 activation was seen (Figure 4) in both cell lines. Activation of caspases is a central mechanism in apoptotic cell death. ${ }^{55}$ Our results showed that caspase 9 is activated early in a CPV infection and activation of caspase 8 was detected later (Figure 4). Caspase 8 is included in death receptor mediated apoptosis while caspase 9 activation is involved in the intrinsic mitochondrial apoptotic pathway. ${ }^{55,56}$ Caspase 8 has been reported to be activated 
in B19-induced apoptosis in erythroid cells and that this type of cell death may be linked to the apoptotic pathway downstream of the TNF receptor. ${ }^{57} \mathrm{CPV}$ enters cells by binding to the transferrin receptor followed by clathrin mediated endocytosis. ${ }^{46,47}$ However, in CPV-infected cells caspase 8 could be activated downstream of death receptors as reported for the B19 virus. Activation of caspase 9 suggests involvement of the mitochondria in cell death. ${ }^{55}$ Also, caspase $3 / 7$ activation was detected in both cell lines (Figure 4) indicating that the cell death occurred in a caspase-dependent manner.

NLFK cells were used to further study the cell death events in CPV-infected cells. Characteristic death events were apparent including nuclear envelope changes, fragmented nuclear components, as well as damaged DNA (Figure 5), along with plasma and mitochondrial membrane depolarization (Figure 6). Dramatic changes in the status of these apoptotic markers could be detected in CPV-infected NLFK cells after the beginning of viral protein synthesis as detected by the NS1 expression (Figure 5a). It has been suggested that the cytotoxicity of a parvoviral infection is caused by the NS1 protein. ${ }^{27,29,30}$ The parvoviral NS1 protein binds DNA and has nickase, helicase, and ATPase activities. ${ }^{58}$ Phosphorylation of histone H2A.X is connected to double-stranded DNA breaks in apoptosis, ${ }^{52,53,59}$ and has been shown to occur even in response to a few breaks. ${ }^{60}$ In CPV-infected cells this histone was phosphorylated and DNA fragmentation, a hallmark of apoptosis, was observed (Figure 5).

In secondary necrosis, plasma membranes of infected cells can be altered. To investigate the consequence of a CPV infection on membranes, membrane potential experiments were conducted (Figure 6). These experiments provided evidence on increased plasma membrane permeability (Figure 6). $\mathrm{DiOC}_{6}(3)$ indicated that mitochondrial membrane potential and possibly also the plasma membrane had changed. The disturbance in the mitochondrial potential seen with DePsipher could account for the induction of apoptosis. ${ }^{61}$ Depolarization of the mitochondrial and plasma membrane are known to occur during apoptosis; in fact, these two phenomena may be interconnected and coordinated by mitochondrial membrane depolarization. ${ }^{62}$ Mitochondrial depolarization will compromise ATP-production and lead to profound changes in cellular metabolism. This has been shown to occur during apoptosis and secondary necrosis. ${ }^{63-65}$

Characteristics of secondary necrosis were observed in our study. Disruption of the cell membrane (Figures 3 and 6), and extensive nuclear membrane blebbing (Figure 5, arrows), provide evidence that secondary necrosis follows apoptosis. This observed cell death of apoptosis and secondary necrosis has been observed in other viruses..$^{20,66,67}$ Apoptotic bodies were not detected in CPV-infected cells (data not shown), but it has been reported earlier that in vivo secondary necrosis appears before apoptotic bodies are formed. ${ }^{68}$ Secondary necrosis takes place in vivo, eg, in the absence of phagocytes or when elimination of apoptotic cells fails. A consequence of secondary necrosis is uncontrolled lysis of dying cells releasing cellular debris that causes inflammation. ${ }^{16}$ Induction of necrosis and inflammation is beneficial in oncolytic virotherapy of cancer cells to activate the immune system. Tumor-associated antigens are released from lysed cells and induce anticancer immunity thus having a prolonged effect of cancer treatment. ${ }^{10}$

The present results are relevant to nanoveterinary medicine, and the area of cancer therapies if one were to use virus-based systems as antineoplastic agents. Due to the fact that overexpression of receptors are characteristic of human tumor cells, ie, TfR, parvovirus-based nanotherapies are being developed. ${ }^{69}$ In addition, rodent parvovirus $\mathrm{H}-1$ was found to exert cytopathic effects on a human hepatocellular carcinoma cell line. ${ }^{70}$ It was also reported that HeLa cells were susceptible to infection by both CPV and FPV. ${ }^{39}$ In these studies lower infection rates were seen mostly due to permissivity of the particular cell line used. Similarly we have shown here that not only can HeLa be infected with CPV, but HepG2 cells can be as well (Table 1). Altogether, parvoviruses are well-suited candidates for vectors in virotherapies and it is noteworthy to understand the cytopathic effects of CPV on cell lines.

Virus-induced effects are cell line dependent as seen in this study by delayed lysis of A72 cells and lower NS1 expression in human cells. When planning to use viruses as nanotools the outcome of the infection has to be studied in each case and for each cell line. CPV has favorable characteristics for exploitation especially in cancer therapy. Infection induces cell cycle arrest and DNA damage leading to cellular lysis. If viruses are used in gene therapy or targeted delivery, oncolytic properties have to be eliminated. Taking into account its lytic infection, the ability to bind human TfR, and its nonpathogenicity in humans, CPV has the potential for use in oncolytic virotherapy.

\section{Acknowledgments/disclosures}

We thank Pirjo Kauppinen and Raimo Pesonen for technical assistance. This study was supported by the Academy of Finland (Contract \# 102161). 


\section{References}

1. Enderlin M, Kleinmann EV, Struyf S, et al. TNF-alpha and the IFN-gamma-inducible protein 10 (IP-10/CXCL-10) delivered by parvoviral vectors act in synergy to induce antitumor effects in mouse glioblastoma. Cancer Gene Ther. 2009;16(2):149-160.

2. Wetzel K, Struyf S, Van Damme J, et al. MCP-3 (CCL7) delivered by parvovirus MVMp reduces tumorigenicity of mouse melanoma cells through activation of T lymphocytes and NK cells. Int J Cancer. 2007; 120(6):1364-1371.

3. Russell SJ, Brandenburger A, Flemming CL, Collins MK, Rommelaere J. Transformation-dependent expression of interleukin genes delivered by a recombinant parvovirus. J Virol. 1992;66(5):2821-2828.

4. Malerba M, Daeffler L, Rommelaere J, Iggo RD. Replicating parvoviruses that target colon cancer cells. J Virol. 2003;77(12):6683-6691.

5. Ponnazhagan S, Weigel KA, Raikwar SP, Mukherjee P, Yoder MC, Srivastava A. Recombinant human parvovirus B19 vectors: erythroid cell-specific delivery and expression of transduced genes. J Virol. 1998; 72(6):5224-5230.

6. Singh P, Destito G, Schneemann A, Manchester M. Canine parvovirus-like particles, a novel nanomaterial for tumor targeting. J Nanobiotechnology. 2006;4:2.

7. Lacroix J, Leuchs B, Li J, et al. Parvovirus H1 selectively induces cytotoxic effects on human neuroblastoma cells. Int J Cancer. 2010; Jan 19. [Epub ahead of print].

8. Herrero Y, Calle M, Cornelis JJ, et al. Parvovirus H-1 infection of human glioma cells leads to complete viral replication and efficient cell killing. Int J Cancer. 2004;109(1):76-84.

9. Liu TC, Kirn D. Gene therapy progress and prospects cancer: oncolytic viruses. Gene Ther. 2008;15(12):877-884

10. Li QX, Liu G, Wong-Staal F. Oncolytic virotherapy as a personalized cancer vaccine. Int J Cancer. 2008;123(3):493-499.

11. Galluzzi L, Maiuri MC, Vitale I, et al. Cell death modalities: classification and pathophysiological implications. Cell Death Differ. 2007;14(7):1237-1243.

12. do Vale A, Costa-Ramos C, Silva DS, et al. Cytochemical and ultrastructural study of anoikis and secondary necrosis in enterocytes detached in vivo. Apoptosis. 2007;12(6):1069-1083.

13. Hebert MJ, Takano T, Holthofer H, Brady HR. Sequential morphologic events during apoptosis of human neutrophils. Modulation by lipoxygenase-derived eicosanoids. J Immunol. 1996;157(7):3105-3115.

14. Majno G, Joris I. Apoptosis, oncosis, and necrosis. An overview of cell death. Am J Pathol. 1995;146(1):3-15.

15. Krysko DV, Vanden Berghe T, D'Herde K, Vandenabeele P. Apoptosis and necrosis: detection, discrimination and phagocytosis. Methods. 2008;44(3):205-221.

16. Silva MT, do Vale A, dos Santos NM. Secondary necrosis in multicellular animals: an outcome of apoptosis with pathogenic implications. Apoptosis. 2008;13(4):463-482.

17. Andersen JL, Le Rouzic E, Planelles V. HIV-1 vpr: mechanisms of G2 arrest and apoptosis. Exp Mol Pathol. 2008;85(1):2-10.

18. Ait-Goughoulte M, Kanda T, Meyer K, Ryerse JS, Ray RB, Ray R. Hepatitis $\mathrm{C}$ virus genotype 1a growth and induction of autophagy. J Virol. 2008;82(5):2241-2249.

19. Abdel-Latif L, Murray BK, Renberg RL, et al. Cell death in bovine parvovirus-infected embryonic bovine tracheal cells is mediated by necrosis rather than apoptosis. J Gen Virol. 2006;87(Pt 9): 2539-2548.

20. Costers S, Lefebvre DJ, Delputte PL, Nauwynck HJ. Porcine reproductive and respiratory syndrome virus modulates apoptosis during replication in alveolar macrophages. Arch Virol. 2008;153(8):1453-1465.

21. Oleksiewicz MB, Alexandersen S. S-phase-dependent cell cycle disturbances caused by aleutian mink disease parvovirus. J Virol. 1997; 71(2):1386-1396.

22. Op De Beeck A, Sobczak-Thepot J, Sirma H, Bourgain F, Brechot C, Caillet-Fauquet P. NS1- and minute virus of mice-induced cell cycle arrest: involvement of p53 and p21(cip1). J Virol. 2001;75(22): 11071-11078.

23. Morita E, Nakashima A, Asao H, Sato H, Sugamura K. Human parvovirus B19 nonstructural protein (NS1) induces cell cycle arrest at G(1) phase. J Virol. 2003;77(5):2915-2921.
24. Morita E, Tada K, Chisaka H, et al. Human parvovirus B19 induces cell cycle arrest at $\mathrm{G}(2)$ phase with accumulation of mitotic cyclins. J Virol. 2001;75(16):7555-7563.

25. Best SM, Wolfinbarger JB, Bloom ME. Caspase activation is required for permissive replication of aleutian mink disease parvovirus in vitro. Virology. 2002;292(2):224-234.

26. Ikeda Y, Shinozuka J, Miyazawa T, et al. Apoptosis in feline panleukopenia virus-infected lymphocytes. J Virol. 1998;72(8):6932-6936.

27. Moffatt S, Yaegashi N, Tada K, Tanaka N, Sugamura K. Human parvovirus B19 nonstructural (NS1) protein induces apoptosis in erythroid lineage cells. J Virol. 1998;72(4):3018-3028.

28. Poole BD, Karetnyi YV, Naides SJ. Parvovirus B19-induced apoptosis of hepatocytes. J Virol. 2004;78(14):7775-7783.

29. Poole BD, Zhou J, Grote A, Schiffenbauer A, Naides SJ. Apoptosis of liver-derived cells induced by parvovirus B19 nonstructural protein. J Virol. 2006;80(8):4114-4121.

30. Rayet B, Lopez-Guerrero JA, Rommelaere J, Dinsart C. Induction of programmed cell death by parvovirus $\mathrm{H}-1$ in U937 cells: connection with the tumor necrosis factor alpha signaling pathway. $J$ Virol. 1998;72(11):8893-8903.

31. Ueno Y, Harada T, Iseki H, Ohshima T, Sugiyama F, Yagami K. Propagation of rat parvovirus in thymic lymphoma cell line C58(NT)d and subsequent appearance of a resistant cell clone after lytic infection. J Virol. 2001;75(8):3965-3970.

32. Ran Z, Rayet B, Rommelaere J, Faisst S. Parvovirus H-1-induced cell death: influence of intracellular NAD consumption on the regulation of necrosis and apoptosis. Virus Res. 1999;65(2):161-174.

33. Di Piazza M, Mader C, Geletneky K, et al. Cytosolic activation of cathepsins mediates parvovirus $\mathrm{H}-1$-induced killing of cisplatin and TRAIL-resistant glioma cells. J Virol. 2007;81(8):4186-4198.

34. Nuesch JP, Rommelaere J. A viral adaptor protein modulating casein kinase II activity induces cytopathic effects in permissive cells. Proc Natl Acad Sci U S A. 2007;104(30):12482-12487.

35. Horiuchi M, Yamaguchi Y, Gojobori T, et al. Differences in the evolutionary pattern of feline panleukopenia virus and canine parvovirus. Virology. 1998;249(2):440-452.

36. Truyen U, Gruenberg A, Chang SF, Obermaier B, Veijalainen P, Parrish CR. Evolution of the feline-subgroup parvoviruses and the control of canine host range in vivo. J Virol. 1995;69(8):4702-4710.

37. Cotmore SF, Tattersall $\mathrm{P}$. The autonomously replicating parvoviruses of vertebrates. Adv Virus Res. 1987;33:91-174.

38. Pollock RVH, Carmichael LE. The Canine Parvoviruses. In: Tijssen P, editor. CRC Handbook of Parvoviruses. Vol 2. Boca Raton: CRC Press, Inc; 1990:113-134.

39. Parker JS, Murphy WJ, Wang D, O’Brien SJ, Parrish CR. Canine and feline parvoviruses can use human or feline transferrin receptors to bind, enter, and infect cells. J Virol. 2001;75(8):3896-3902.

40. Bauder B, Suchy A, Gabler C, Weissenbock H. Apoptosis in feline panleukopenia and canine parvovirus enteritis. J Vet Med B Infect Dis Vet Public Health. 2000;47(10):775-784.

41. Parrish CR. Mapping specific functions in the capsid structure of canine parvovirus and feline panleukopenia virus using infectious plasmid clones. Virology. 1991;183(1):195-205.

42. Crissman HA, Steinkamp JA. Rapid, simultaneous measurement of DNA, protein, and cell volume in single cells from large mammalian cell populations. J Cell Biol. 1973;59(3):766-771.

43. Koopman G, Reutelingsperger CP, Kuijten GA, Keehnen RM, Pals ST, van Oers MH. Annexin V for flow cytometric detection of phosphatidylserine expression on B cells undergoing apoptosis. Blood. 1994;84(5):1415-1420.

44. Solovyan V, Salminen A. A rapid and efficient method for preparation of genomic DNA suitable for analysis of both high and low molecular weight DNA fragmentation during neuronal apoptosis. Brain Res Brain Res Protoc. 1999;4(3):335-340.

45. Bortner CD, Cidlowski JA. Caspase independent/dependent regulation of $\mathrm{K}(+)$, cell shrinkage, and mitochondrial membrane potential during lymphocyte apoptosis. J Biol Chem. 1999; 274(31):21953-21962. 
46. Parker JS, Parrish CR. Cellular uptake and infection by canine parvovirus involves rapid dynamin-regulated clathrin-mediated endocytosis, followed by slower intracellular trafficking. J Virol. 2000; 74(4):1919-1930.

47. Suikkanen S, Saajarvi K, Hirsimaki J, et al. Role of recycling endosomes and lysosomes in dynein-dependent entry of canine parvovirus. J Virol. 2002;76(9):4401-4411.

48. Suikkanen S, Aaltonen T, Nevalainen M, et al. Exploitation of microtubule cytoskeleton and dynein during parvoviral traffic toward the nucleus. J Virol. 2003;77(19):10270-10279.

49. Suikkanen S, Antila M, Jaatinen A, Vihinen-Ranta M, Vuento M. Release of canine parvovirus from endocytic vesicles. Virology. 2003; 316(2):267-280.

50. Vihinen-Ranta M, Kalela A, Makinen P, Kakkola L, Marjomaki V, Vuento M. Intracellular route of canine parvovirus entry. J Virol. 1998; 72(1):802-806.

51. Martin SJ, Reutelingsperger CP, McGahon AJ, et al. Early redistribution of plasma membrane phosphatidylserine is a general feature of apoptosis regardless of the initiating stimulus: inhibition by overexpression of bcl-2 and abl. J Exp Med. 1995;182(5):1545-1556.

52. Rogakou EP, Nieves-Neira W, Boon C, PommierY, Bonner WM. Initiation of DNA fragmentation during apoptosis induces phosphorylation of H2AX histone at serine 139. J Biol Chem. 2000;275(13):9390-9395.

53. Talasz H, Helliger W, Sarg B, Debbage PL, Puschendorf B, Lindner H. Hyperphosphorylation of histone H2A.X and dephosphorylation of histone $\mathrm{H} 1$ subtypes in the course of apoptosis. Cell Death Differ. 2002;9(1):27-39.

54. Overbeeke R, Steffens-Nakken H, Vermes I, Reutelingsperger C, Haanen C. Early features of apoptosis detected by four different flow cytometry assays. Apoptosis. 1998;3(2):115-121.

55. Kumar S. Caspase function in programmed cell death. Cell Death Differ. 2007;14(1):32-43.

56. Chang HY, Yang X. Proteases for cell suicide: functions and regulation of caspases. Microbiol Mol Biol Rev. 2000;64(4):821-846.

57. Sol N, Le Junter J, Vassias I, et al. Possible interactions between the NS-1 protein and tumor necrosis factor alpha pathways in erythroid cell apoptosis induced by human parvovirus B19. J Virol. 1999; 73(10):8762-8770.

58. Cotmore SF, Tattersall P. DNA replication in the autonomous parvoviruses. Semin Virol. 1995;6(5):271-281.
59. Lu C, Zhu F, Cho YY, et al. Cell apoptosis: requirement of H2A.X in DNA ladder formation, but not for the activation of caspase-3. Mol Cell. 2006;23(1):121-132.

60. Bakkenist CJ, Kastan MB. DNA damage activates ATM through intermolecular autophosphorylation and dimer dissociation. Nature. 2003;421(6922):499-506.

61. Green DR, Reed JC. Mitochondria and apoptosis. Science. 1998; 281(5381):1309-1312.

62. Dussmann H, Rehm M, Kogel D, Prehn JH. Outer mitochondrial membrane permeabilization during apoptosis triggers caspase-independent mitochondrial and caspase-dependent plasma membrane potential depolarization: a single-cell analysis. J Cell Sci. 2003;116(Pt 3):525-536.

63. Chen SP, Yang HL, Her GM, et al. Betanodavirus induces phosphatidylserine exposure and loss of mitochondrial membrane potential in secondary necrotic cells, both of which are blocked by bongkrekic acid. Virology. 2006;347(2):379-391.

64. Matsuyama S, Llopis J, Deveraux QL, Tsien RY, Reed JC. Changes in intramitochondrial and cytosolic $\mathrm{pH}$ : early events that modulate caspase activation during apoptosis. Nat Cell Biol. 2000;2(6):318-325.

65. Tiefenthaler M, Amberger A, Bacher N, et al. Increased lactate production follows loss of mitochondrial membrane potential during apoptosis of human leukaemia cells. Br J Haematol. 2001;114(3):574-580.

66. Chen SP, Wu JL, Su YC, Hong JR. Anti-bcl-2 family members, zfBcl$\mathrm{x}(\mathrm{L})$ and zfMcl-1a, prevent cytochrome c release from cells undergoing betanodavirus-induced secondary necrotic cell death. Apoptosis. 2007;12(6):1043-1060.

67. Hong JR, Lin TL, Hsu YL, Wu JL. Apoptosis precedes necrosis of fish cell line with infectious pancreatic necrosis virus infection. Virology. 1998;250(1):76-84.

68. Goldspink DF, Burniston JG, Ellison GM, Clark WA, Tan LB. Catecholamine-induced apoptosis and necrosis in cardiac and skeletal myocytes of the rat in vivo: The same or separate death pathways? Exp Physiol. 2004;89(4):407-416.

69. Singh P. Tumor targeting using canine parvovirus nanoparticles. Curr Top Microbiol Immunol. 2009;327:123-141.

70. Li J, Werner E, Hergenhahn M, et al. Expression profiling of human hepatoma cells reveals global repression of genes involved in cell proliferation, growth, and apoptosis upon infection with parvovirus H-1. J Virol. 2005;79(4):2274-2286.
International Journal of Nanomedicine

\section{Publish your work in this journal}

The International Journal of Nanomedicine is an international, peerreviewed journal focusing on the application of nanotechnology in diagnostics, therapeutics, and drug delivery systems throughout the biomedical field. This journal is indexed on PubMed Central, MedLine, CAS, SciSearch $\AA$, Current Contents ${ }^{\circledR} /$ Clinical Medicine,

\section{Dovepress}

Journal Citation Reports/Science Edition, EMBase, Scopus and the Elsevier Bibliographic databases. The manuscript management system is completely online and includes a very quick and fair peer-review system, which is all easy to use. Visit http://www.dovepress.com/ testimonials.php to read real quotes from published authors. 